EXTENDED REPORT

\title{
Cost effectiveness of foldable multifocal intraocular lenses compared to foldable monofocal intraocular lenses for cataract surgery
}

\author{
M G T Dolders, M D Nijkamp, R M M A Nuijts, B van den Borne, F Hendrikse, A Ament, W Groot
}

Br J Ophthalmol 2004;88:1163-1168. doi: 10.1136/bjo.2003.035527

See end of article for authors' affiliations

Correspondence to: M G T Dolders, MHSc, Maastricht University, Department of Health Organisation, Policy and Economics - UNS 40, PO Box 616, 6200 Maastricht, Netherlands; m.dolders@beoz. unimaas.nl

Accepted for publication 1 January 2004

\begin{abstract}
Aim: To analyse the cost effectiveness of foldable monofocal intraocular lenses (IOLs) compared to foldable multifocal IOLs in cataract surgery alongside a prospective, multicentre randomised clinical trial (RCT). Methods: Patients underwent cataract surgery with bilateral monofocal $(n=97)$ or multifocal $(n=93)$ IOL implantation. Cost data and patient preferences, using the visual analogue scale (VAS), the time trade-off (TTO), and the standard gamble (SG) technique were obtained preoperatively and postoperatively by structured interviews. The incremental costs (multifocal minus monofocal), mean costs per patient, and differences in preferences were computed.

Results: Mean costs for glasses per patient in the monofocal group were $€ 41.67$ and in the multifocal group $€ 149.58$. The difference in costs between the multifocal and monofocal group was $€-92.09$ and was statistically significant $(p=0.008)$. No significant differences were found in total costs or in effectiveness between the monofocal and multifocal IOL group.

Conclusion: The cost effectiveness of multifocal IOLs is reduced to a cost minimisation analysis, because of the inability to demonstrate significant differences in effects. The use of multifocal IOLs in cataract surgery resulted in a significant reduction in costs for patient's postoperative spectacles.
\end{abstract}

M odern cataract surgery enables treatment of cataract and (oncoming) presbyopia in cataract patients. ${ }^{1}$ An ideal intraocular lens (IOL) would simulate the original function of the crystalline lens and provide the patient with multifocal vision. ${ }^{1-3}$

Clinical studies have shown improved uncorrected near visual acuity and a decreased spectacle dependency for patients with a multifocal IOL compared to patients with monofocal lens implantation. ${ }^{4}$ It is hypothesised that this decreased spectacle dependency results in vision related and generic health related quality of life (HRQoL) differences between patients with monofocal and multifocal IOLs. ${ }^{5-7}$ Differences in the effectiveness can be related to the possible differences in costs, resulting in a cost effectiveness analysis.

Up to now, there is one cost effectiveness study that compares cataract surgery with implantation of bilateral monofocal and multifocal IOLs. ${ }^{8}$ This study reported the cost effectiveness of each treatment using the healthcare payer perspective and divided the average cost per patient by the proportion of patients experiencing a particular vision related outcome, such as costs per spectacle free patient.

A specific type of a cost effectiveness analysis (CEA) is a cost utility analysis (CUA). ${ }^{9}$ In a CUA consequences are measured in quality adjusted life years (QALYs). A QALY combines quantity of life (in years) with quality of life (expressed in utilities/preferences) in one measure. A utility is a preference for a certain health state expressed in a cardinal number between 0 (death/worst imaginable health status) and 1 (perfect health/best imaginable health status). The term utility and preference will be used interchangeably in this article. The results of a CUA are reported as costs per QALY gained. By using this standard, CUAs in ophthalmology can be compared to CUAs in other healthcare fields. CUAs are particularly useful for decision making about the allocation of scarce resources to maximise social welfare. ${ }^{9}$
The aim of the present study was to conduct a cost utility analysis of monofocal and multifocal IOLs in cataract surgery, following a societal perspective. ${ }^{9}{ }^{10}$

\section{PATIENTS AND METHODS}

Participants

The medical files of 1218 consecutive cataract patients awaiting surgery were screened for inclusion in a randomised controlled trial (RCT) determining patient satisfaction after surgery. ${ }^{11}$ The inclusion criteria were bilateral senile cataract, preoperative keratometric astigmatism $\leqslant 1.5$ dioptres (D), axial length between $19.5 \mathrm{~mm}$ and $26 \mathrm{~mm}$, and preoperative sphere between $-6 \mathrm{D}$ and $+4 \mathrm{D}$. Exclusion criteria were professional night driving, ocular co-morbidity, mental retardation, inability to complete the questionnaire in Dutch, and pseudophakia. Additionally, patients with perioperative or postoperative complications were excluded. Figure 1 represents the flow of patients through the trial. The surgery was performed at one of the following outpatient centres: Atrium Medical Centre Heerlen (AMCH), University Hospital Maastricht (UHM), and Medical Centre Maastricht Annadal (MCMA). The nature and purpose of this study, including (side) effects of the treatment were explained to each patient by the ophthalmologist in attendance. A patient information brochure and an informed consent form were sent to all selected patients awaiting surgery. The ethics committees of the trial centres approved this research protocol. Enrolment of 190 patients occurred from August 1999 until January 2001.

Abbreviations: CEA, cost effectiveness analysis; CUA, cost utility analysis; HRQoL, health related quality of life; IOLs, intraocular lenses; QALYs, quality adjusted life years; RCT, randomised clinical trial; SG, standard gamble; TTO, time trade-off; VAS, visual analogue scale 


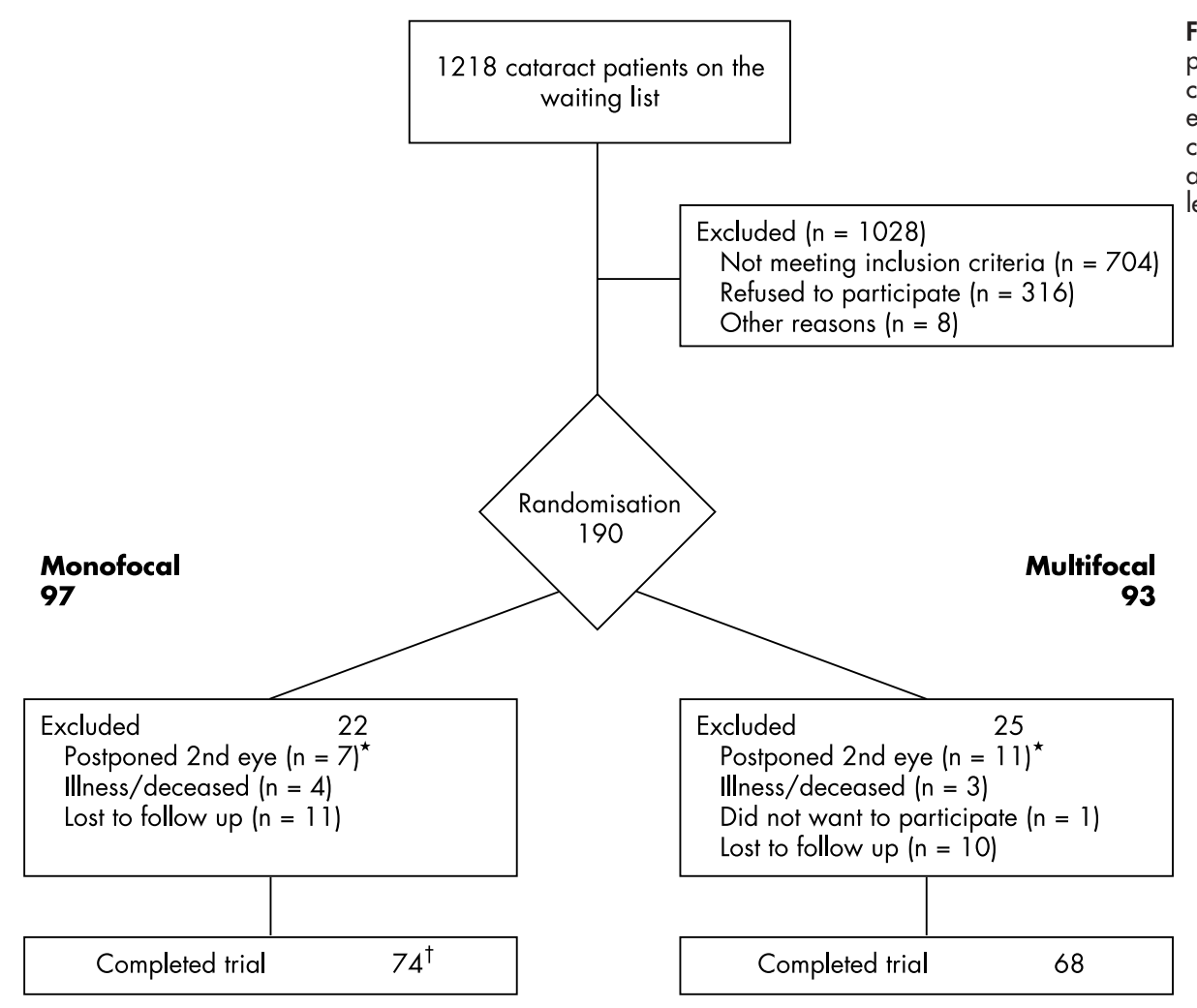

Figure 1 Trial profile. *In the trial profile of the effectiveness study, one cataract patient in the spherical equivalent $>1.5 \mathrm{D}$ group. ${ }^{1 "}$ †One cataract patient was intended to receive a monofocal lens, but received another lens at the first eye surgery.

Patients were masked for their treatment condition until the first postoperative visit. Preoperatively, ophthalmologists and interviewers were unaware of which type of lens a patient received. Since there were observable differences between both lenses masking of ophthalmologists and interviewers until study completion was not feasible. ${ }^{11}$ Patients were randomised 1 week before surgery (when the power of the implant lens was computed) and after giving informed consent.

Group 1 patients received bilateral monofocal IOLs; group 2 bilateral multifocal IOLs. The patients were interviewed $1-2$ weeks before first eye surgery (tl), 3 months after first eye surgery (t2), and up to 3 months postoperatively after second eye surgery (t3). The interval between first and second eye surgery was approximately 16 weeks.

The surgical procedure was standardised (see table 1). Phacoemulsification using a monofocal foldable IOL (AMOPhacoFlexII SI40 NB, Allergan, Irvine, CA, USA) or a multifocal foldable IOL (AMOArray SA 40 N, Allergan, Irvine, CA, USA) was performed. Both IOLs were structurally identical differing only in the contour of the front surface of the optic.

Structured interviews took place at the UHM department of ophthalmology by two experienced interviewers.

\section{Costs}

The direct healthcare and non-healthcare costs and the indirect costs were considered in the economic analysis. The

\section{Table 1 Standardised surgical procedure}

Small $3.2 \mathrm{~mm}$ posterior limbal incision Sub-Tenon retrobulbar anaesthesia No stitch technique in wound closure Postoperative topical steroids and antibiotics Postoperative refraction aimed at emmetropia costs for the IOLs were derived from the hospital administration. Since the surgical procedure was similar all patients, and the surgeons were exchangeable between the three centres, the costs of surgery were assumed equal for both IOLs. Drummond et $a l^{10}$ suggest ignoring the costs that are common to both treatments, because they will not affect the choice between the given treatments. Therefore, the costs of the surgical procedure and other clinically relevant costs (for example, diagnosis, postoperative tests, and consultation costs) were excluded from the economic analysis. ${ }^{8}$ Direct non-healthcare costs (for example, transportation costs) were assumed to be equally distributed between the two IOL groups, ${ }^{8}$ excluding these costs from the analysis. ${ }^{10}$ Indirect healthcare costs (for example, disability for work) were assumed to be distributed equally between the two groups, and were therefore also excluded from the analysis.

\section{Effectiveness}

The effectiveness of the surgery was measured by means of patient preferences, which reflect the utilities or values assigned to a patient's self reported health state. ${ }^{10}$ Self reported health state was measured with the EuroQol-5D (EQ-5D) and categorised into three levels of severity: healthy, (very) mild, (very) severe. ${ }^{12}{ }^{13}$

Measurement of patient preferences used non-preference based (visual analogue scale) and preference based instruments (time trade-off and standard gamble). ${ }^{14}$ The visual analogue scale (VAS) is a horizontal $10 \mathrm{~cm}$ line on which patients can mark their current generic health state. A report mark (RM) was used instead of the VAS if patients were unable to see the $10 \mathrm{~cm}$ line. VAS and RM ranged from 0 to 10 and directly equal their preference. Although both preferences were measured on the same scale, we transformed both to a $0-1$ scale representing the worst HRQoL state $(0)$ or the best HRQoL state (1) to allow comparison of non-preference based values with preference based values or utilities. VAS and RM scores correlated highly (t1: $r=0.63$, 
$\mathrm{t} 2: r=0.71, \mathrm{t} 3: r=0.66$, all significant at the 0.001 level). To avoid multicollinearity, the VAS was used in the statistical analyses, because it represents a continuous scale and is more commonly used in the economic literature.

The time trade-off (TTO) was defined as a choice between two alternatives. In the present study, the first alternative was "living 10 years with cataract," the second "living 10 years in full health." The second alternative was then changed from 10 to 9 years, from 9 to 8 years and so on, until the patient was indifferent about the two alternatives. To compute the preference for cataract, 0-10 scales were transformed to $0-1$ scales using the formula: cataract $=$ number of years in full health/10.

The standard gamble (SG) is a technique in which choices are offered to patients between living with cataract for the remainder of their lives or undergoing surgery with a chance of returning to perfect health $(p)$ or a chance that the surgery results in blindness $(1-p)$. The probability of surgery success is varied until the patient is indifferent about remaining in the cataract state or risking surgery. At this indifference point the utility equals $\mathrm{p}$. The probabilities are measured as proportions. In economic evaluations the utility scale is a 0-1 scale with end points being perfect health and death. In the present study the end point was blindness. Utilities were recalculated to a $0-1$ scale with end points as perfect health and death by multiplying chance $(1-p)$ by the mean utility for blindness (no light perception) ${ }^{15}$ and adding chance $(p)$. Visual aids were used to enhance the comprehensibility of the probabilities for TTO and SG. ${ }^{16}$

\section{Statistical analyses}

Power calculations were performed to determine the sample size necessary to draw reliable statistical conclusions on clinical parameters. Economic criteria ${ }^{17}$ could not be applied, since this was the first cost effectiveness study comparing IOLs from a societal perspective. Patients measured at $\mathrm{t} 1, \mathrm{t} 2$, and $\mathrm{t} 3$ were analysed $(\mathrm{n}=143)$ on an intention to treat base. Independent $t$ tests and $\chi^{2}$ tests for proportions were applied to assess selection caused by dropout and to assess differences in baseline characteristics between monofocal and multifocal IOL patients. The distribution of the data was tested for normality with the Kolgomorov-Smirnov test. Since costs were non-normally distributed the non-parametric Mann-Whitney $U$ test was used to analyse the differences in costs for spectacles between both IOL groups. Logistic regression analysis was used to determine differences in preferences and change in general health status between both IOL groups. Pretest differences were controlled for by entering general health status and preferences at tl in the first step of the analysis. In the dropout analysis, dropouts were compared to patients who completed the interviews regarding the following variables: demographic characteristics, type of IOL, type of preoperative glasses, general health status, and preferences. Whenever possible, the reasons for dropout were traced. Furthermore, the same variables and the presence or absence of general co-morbidity were used to compare baseline characteristics between monofocal and multifocal IOL groups. The level of significance was $p<0.05$. Analyses were performed using SPSS 10.0 (Chicago, IL, USA).

\begin{tabular}{|c|c|c|c|}
\hline Demographic characteristics (\%)† & $\begin{array}{l}\text { Monofocal IOL (0) } \\
(n=75)\end{array}$ & $\begin{array}{l}\text { Multifocal IOL (1) } \\
(\mathrm{n}=68)\end{array}$ & p Value* \\
\hline Age (mean, SD) & $72.2(7.9)$ & $72.9(7.0)$ & 0.59 \\
\hline Female:male ratio & $56.0: 44.0$ & $64.7: 35.3$ & \\
\hline Marital status: & 61.3 & 60.3 & \\
\hline Married/living together (0) & 38.7 & 39.7 & 0.90 \\
\hline Single/divorced/widowed (1) & 56.0 & 61.8 & 0.67 \\
\hline Education: & 34.7 & 32.3 & \\
\hline Low (1) & 9.3 & 5.9 & \\
\hline \multicolumn{4}{|l|}{ Middle (2) } \\
\hline \multicolumn{4}{|l|}{ High (3) } \\
\hline \multicolumn{3}{|l|}{ Vision related characteristics (\%)‡: } & 0.18 \\
\hline Type of glasses $\%$ : & 9.3 & 13.2 & \\
\hline Reading (1) & 73.3 & 80.9 & \\
\hline Bifocal or multifocal (2) & 10.7 & 4.4 & \\
\hline Distance (3) & & & \\
\hline \multicolumn{4}{|l|}{ General co-morbidity (\%): } \\
\hline No & 41.3 & 42.6 & 0.87 \\
\hline Yes & 58.7 & 57.4 & \\
\hline \multicolumn{3}{|l|}{ General health status, EQ-5D (\%)‡: } & $<0.01$ \\
\hline Healthy (1) & 36.0 & 26.5 & \\
\hline (Very) mild (2) & 60.0 & 47.0 & \\
\hline (Very) severe (3) & 4.0 & 26.5 & \\
\hline \multicolumn{4}{|l|}{ Preferences (mean, SD)§: } \\
\hline VAS§§ & $0.78(0.19)$ & $0.66(0.22)$ & $<0.01$ \\
\hline тоО & $0.68(0.28)$ & $0.70(0.26)$ & 0.83 \\
\hline SG†十，㧊 & $0.94(0.06)$ & $0.95(0.06)$ & 0.06 \\
\hline \multicolumn{4}{|c|}{ 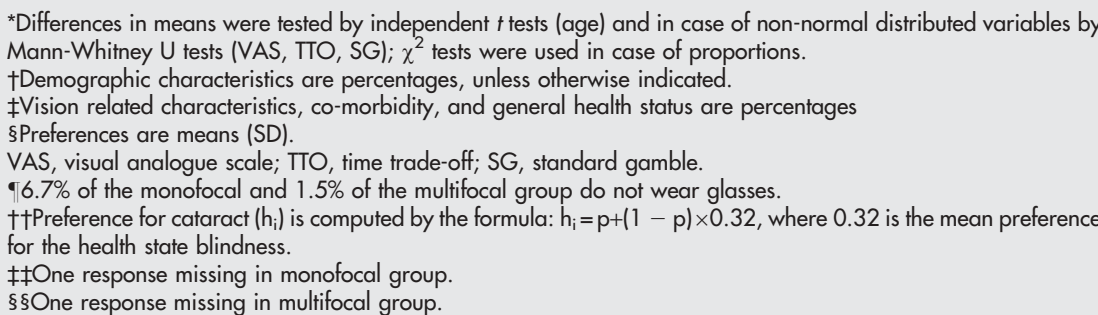 } \\
\hline
\end{tabular}


Table 3 Mean (SD) clinical outcomes of cataract patients by treatment group

\begin{tabular}{|c|c|c|c|c|c|c|c|c|}
\hline & \multicolumn{3}{|c|}{ Monofocal IOL (0) (n=75) } & \multicolumn{3}{|c|}{ Multifocal IOL (1) (n=68) } & \multirow[b]{2}{*}{ p Value* } & \multirow[b]{2}{*}{ p Value } \\
\hline & tl & †2 & t3 & +1 & t2 & t3 & & \\
\hline VA (1 st eye) & $0.46(0.27)$ & $0.12(0.22)$ & NA & $0.49(0.27)$ & $0.13(0.17)$ & NA & NS & NS \\
\hline VA (2nd eye) & $0.31(0.22)$ & NA & $0.07(0.14)$ & $0.28(0.19)$ & NA & $0.09(0.16)$ & NS & \\
\hline SE (1st eye) & $-0.31(2.14)$ & $-0.31(0.77)$ & NA & $0.29(2.08)$ & $0.06(0.66)$ & NA & $<0.01$ & \\
\hline SE (2nd eye) & $-0.16(2.21)$ & NA & $-0.42(0.77)$ & $0.60(1.95)$ & NA & $0.14(0.58)$ & NA & $<0.001$ \\
\hline \multicolumn{9}{|c|}{$\begin{array}{l}\text { VA ( } 1 \text { st eye) = present corrected visual acuity of the first eye (RE or LE) in I } \\
\text { VA ( } 2 \text { nd eye) = present corrected visual acuity of the second eye (RE or LE) } \\
\text { SE ( } 1 \text { st eye) = refraction error in spherical equivalent of the first eye. } \\
\text { SE ( } 2 \text { nd eye) = refraction error in spherical equivalent of the second eye. } \\
\text { Visual acuity and refraction error are means (SD). } \\
\text { NA = not applicable, NS, not significant. } \\
\text { *Differences between monofocal and multifocal IOL groups at } t 2 \text {. } \\
\text { tDifferences between monofocal and multifocal IOL groups at }+3 \text {. }\end{array}$} \\
\hline
\end{tabular}

Patients reported the costs of glasses in Dutch guilders. In the period 1999-2002 the conversion from Dutch guilders to euros was fixed. The recalculation was: $1 €=2.20371$ Dutch guilders. Euros can be converted into US\$ by using the exchange rate in the period that patients were included. This exchange rate varies from $1 €=0.85$ US $\$$ to $1 €=1.07$ US\$. ${ }^{18}$

\section{RESULTS}

\section{Representativeness of study group}

Eligibility criteria were met for 514 cataract patients $(42.2 \%)$ (fig 1). The main reason for ineligibility was pseudophakia. Further information regarding differences in representativeness of the study group are explained in the effectiveness study by Nijkamp. ${ }^{11}$

No significant differences were found in the dropout analysis, indicating that there was no selection bias. Known reasons for dropout were (acquired) ocular co-morbidity $(n=6)$, other illnesses or deceased $(n=7)$, unwilling to continue participation $(\mathrm{n}=1)$, and unreachable patients $(\mathrm{n}=10)$. Twenty one cataract patients postponed second eye surgery, of whom two with multifocal IOL implantation, reported halos at night.

\section{Baseline characteristics}

Table 2 presents the baseline characteristics of the monofocal and multifocal group completing all measurements. Demographics, vision related characteristics, and co-morbidity were similar for both groups. The general health status of patients differed significantly $(\mathrm{p}<0.01)$ between the two groups. In the monofocal group $36.0 \%(\mathrm{n}=27)$ were classified as healthy, $60.0 \%(\mathrm{n}=45)$ as having a mild disease, and $4.0 \%(\mathrm{n}=3)$ as severely ill. The percentages in the multifocal group were $26.5 \%(n=18), 47.0 \%(n=32)$, and
26.5\% $(n=18)$, respectively. Severely ill patients were patients with different co-morbidity, which was reflected in the generic quality of life instrument. These patients have some difficulties to walk, bath, and dress themselves and perform their daily activities. They also were likely to have some pain and have some problems with anxiety. According to Dolan ${ }^{13}$ these patients classify themselves as severely ill, which is not reflected in the general co-morbidity. In contrast with self reported health status, cataract patients did not differ significantly in general co-morbidity $(p=0.87)$. Since the randomisation was based on ocular co-morbidity, it was possible to find a significant difference between monofocal and multifocal patients for self reported general health status. Thus, general health status is a known covariate and needs to be included in the statistical analyses. Statistical baseline differences between the monofocal and multifocal group were found regarding the VAS valuation of the general health status. The preference for the monofocal group, was $0.78(0.19)$ and for the multifocal group $0.66(0.22)(\mathrm{p}<0.01)$. Controlling for these baseline differences by including them as covariates in the regression model was applied.

\section{Clinical outcome parameters}

Table 3 presents the present corrected visual acuity (VA) in $\log$ MAR and postoperative refraction error in spherical equivalents (SE). VA was not significantly different between the two IOL groups. The monofocal group showed a myopic SE compared to the multifocal group at $\mathrm{tl}(\mathrm{p}<0.01)$ and at $\mathrm{t} 2$ $(\mathrm{p}<0.001)$.

\section{Costs}

Table 4 presents the costs for monofocal and multifocal IOL for both eyes and the mean direct patient costs. No

Table 4 Mean costs per patient by treatment group $(€)$

\begin{tabular}{|c|c|c|c|}
\hline & $\begin{array}{l}\text { Monofocal IOL } \\
(n=75)\end{array}$ & $\begin{array}{l}\text { Multifocal IOL } \\
(n=68)\end{array}$ & Incremental costs \\
\hline \multicolumn{4}{|l|}{ Direct hospital costs } \\
\hline \multicolumn{4}{|l|}{ Direct patient costs (mean, SD) } \\
\hline Reading glasses & $29.91(78.45)$ & $32.17(64.01)$ & 2.26 \\
\hline Bifocal glasses & 67.47 (133.22) & $64.02(147.07)$ & -3.45 \\
\hline Multifocal glasses & $128.19(230.79)$ & $46.40(140.21)$ & $-81.79 *$ \\
\hline Distance glasses & $16.11(51.99)$ & $5.17(24.61)$ & -10.94 \\
\hline Non-refractive glasses & $0.00(0.00)$ & $1.82(5.76)$ & $1.82^{* *}$ \\
\hline Subtotal direct patients costs $(95 \% \mathrm{Cl})$ & 241.67 (219.91) & 149.58 (185.01) & $-92.09^{* * *}(-159.06$ to -25.12$)$ \\
\hline Total costs per patient $(95 \% \mathrm{Cl})$ & 400.49 (219.91) & $399.16(185.01)$ & $-1.33(-68.30$ to 65.34$)$ \\
\hline \multicolumn{4}{|c|}{$\begin{array}{l}\text { *Mann-Whitney } U \text { test: } U=-2.406, p=0.016 \\
{ }^{* *} \text { Mann-Whitney } U \text { test: } U=-2.838, p=0.005 \\
{ }^{* * *} \text { Mann-Whitney } U \text { test: } U=-2.670, p=0.008 \text {. } \\
\text { †Standard deviation not applicable. } \\
95 \% \mathrm{Cl}, 95 \% \text { confidence interval. }\end{array}$} \\
\hline
\end{tabular}


Table 5 Mean (SD) utilities of monofocal and multifocal IOL patients over time controlled for baseline differences ( $n=143$ )

\begin{tabular}{|c|c|c|c|c|c|c|c|c|}
\hline & \multicolumn{3}{|c|}{ Monofocal IOL (0) $(n=75)$} & \multicolumn{3}{|c|}{ Multifocal IOL (1) (n=68) } & \multirow[b]{2}{*}{ Odds ratio $(95 \% \mathrm{Cl}) \dagger$} & \multirow[b]{2}{*}{ Odds ratio $(95 \% \mathrm{Cl}) \ddagger$} \\
\hline & t1 & t2 & t3 & 11 & 12 & +3 & & \\
\hline VAS & $0.78(0.19)$ & $0.80(0.19)$ & $0.79(0.17)$ & $0.66(0.22)$ & $0.76(0.22)$ & $0.70(0.24)$ & $0.08^{*}(0.01$ to 0.56$)$ & $0.10 *(0.02$ to 0.64$)$ \\
\hline тTO & $0.68(0.28)$ & $0.74(0.28)$ & $0.67(0.29)$ & $0.70(0.26)$ & $0.70(0.30)$ & $0.62(0.28)$ & NS & NS \\
\hline SG & $0.94(0.06)$ & $0.95(0.06)$ & $0.94(0.05)$ & $0.95(0.06)$ & $0.94(0.06)$ & $0.93(0.07)$ & NS & NS \\
\hline
\end{tabular}

$95 \% \mathrm{Cl}, 95 \%$ confidence interval; NS, not significant; VAS, visual analogue scale; TTO, time trade-off; SG, standard gamble.

†Odds ratios calculated between $\mathrm{t} 2$ and $\mathrm{t} 1$.

$\neq$ Odds ratios calculated between $\mathrm{t} 3$ and $\mathrm{t} 1$.

${ }^{*} \mathrm{p}<0.05$.

significant differences in total patient costs were found. Significant costs differences between the monofocal and multifocal IOL were found for the out of pocket expenses for multifocal glasses $(U=-2.406, p=0.016)$ and for nonrefractive glasses $(U=-2.838, p=0.005)$. The mean costs for multifocal or non-refractive glasses per patient in the monofocal group were $€ 128.19$ (€230.79) and $€ 0.00$, and in the multifocal group $€ 46.40$ ( $€ 140.21)$ and $€ 1.82$ (€5.76), respectively. Cumulating all types of glasses a significant difference was found in the direct patient costs $(\mathrm{U}=-2.670$, $\mathrm{p}=0.008)$. The monofocal group spent more money on glasses $(€ 241.67(€ 219.91))$ than the multifocal group $(€ 149.58(€ 185.01))$, because of the costs of the relatively expensive multifocal glasses. As some patients in the multifocal group were habitually used to wear glasses, they spent money on non-refractive glasses.

\section{Effectiveness}

Table 5 shows the mean utilities of monofocal and multifocal IOL implanted patients after first ( $\mathrm{t} 2$ ) and second ( $\mathrm{t} 3$ ) eye surgery. Although we controlled for the preoperative difference in VAS preferences between the two groups, significant differences in VAS preferences after first eye surgery were not found. The significant odds ratio (OR $=0.08,95 \%$ confidence interval $(\mathrm{CI})=0.01-0.56)$ was explained by the preoperative difference in VAS preferences. At tl the mean VAS preference was $0.78(0.19)$ for the monofocal group and $0.66(0.22)$ for the multifocal group.

After second eye surgery a significant odds ratio ( $\mathrm{OR}=0.10,95 \% \mathrm{CI}=0.02$ to 0.64 ) was found between the monofocal and multifocal group. This difference was also explained by the preoperative difference in VAS preferences. Statistical differences in TTO and SG were not found between monofocal and multifocal IOL patients.

\section{DISCUSSION}

This paper described a cost utility analysis of foldable multifocal and monofocal IOLs in cataract surgery applying a societal perspective. In contrast with to the study of Orme et $a l^{8}$ this study revealed that cataract surgery implanting a monofocal or multifocal IOL is equally cost effective. The present study used prospectively collected effectiveness data and measured costs alongside an RCT. Since an RCT is the "gold standard" to obtain unbiased, reliable data we have reason to believe that our data are more representative of the reality. ${ }^{1}$

The present study was performed without financial interest and offers an unbiased representation of the cost effectiveness of multifocal IOLs. ${ }^{19-21}$

Effectiveness in the present study was measured in terms of generic HRQoL. We assumed a relation between visual acuity loss and HRQOL for cataract based on a study comparing the quality of life in patients with visual acuity loss due to diabetic retinopathy and visual acuity loss because of age related macular degeneration. ${ }^{22}$
Furthermore, this study showed that the savings in the direct patient costs compensate for the additional direct healthcare costs for the multifocal IOL. Although policy makers may not welcome the fact that costs in the healthcare sector will be saved outside the healthcare sector, from a patient perspective this is a positive result.

Some remarks about the present study can be made. Firstly, patient preferences were used as outcome measure. To fully carry through the societal perspective, societal preferences should be used.

Secondly, significant differences in effectiveness in this prospective study were not found. This could be attributed to an adaptation effect ${ }^{23-25}$ or to a problem with construct validity. Patients adapt to their condition and as a consequence they value the pretreatment quality of life generally higher than one would expect given their condition. Posttreatment, patients value their pretreatment quality of life generally lower, because of a change in internal standards. This phenomenon is known as response shift. ${ }^{23}$ VAS, TTO, and SG correlated significantly $(\mathrm{p}<0.01)$. Correlations varied from 0.40 to 0.43 , indicating that the underlying construct is similar.

To choose an economic analysis alongside a clinical trial is sometimes problematic. ${ }^{26}$ Although we chose to perform a cost utility analysis with costs per QALY as the main outcome parameter, the results indicate the inappropriateness of this economic design. If outcomes are equivalent between two alternatives compared, the economic analysis is reduced to a cost minimisation analysis.

In view of our results we believe that a reduction in costs for multifocal glasses for patients with a multifocal IOL is beyond the goal of resource allocation in the health care sector. However, seen from a societal perspective, this should be included in the decision making process, since a reduction in costs for patients maximises social welfare, which is the goal of resource allocation. ${ }^{9}$ Nevertheless, individual decisions are not only based on costs but on patients' acceptance of night time halos in exchange for decreased spectacle dependence for near vision.

\section{ACKNOWLEDGEMENTS}

We are indebted to Eddy MM Adang, PhD for theoretical assistance. We would like to thank $J$ de Brabander, PhD, MJC Kooijman-de Groot, MD, V Ashish Nabar, MD, and E Brounts, RA, for their contribution to this study.

\section{Authors' affiliations}

M G T Dolders, A Ament, W Groot, Maastricht University, Department of Health Organisation, Policy and Economics (HOPE), Maastricht, Netherlands

M G T Dolders, M D Nijkamp, B van den Borne, A Ament, W Groot, Care and Public Health Research Institute (CAPHRI), Maastricht, Netherlands

M D Nijkamp, F Hendrikse, Eye Research Institute Maastricht (ERIM), Maastricht, Netherlands 
R M M A Nuijts, F Hendrikse, University Hospital Maastricht, Department of Ophthalmology, Maastricht, Netherlands

B van den Borne, Maastricht University, Department of Health Education, Maastricht, Netherlands

The authors have not received any financial support.

The authors have no financial or propriety interest related to this article.

\section{REFERENCES}

1 Javitt JC, Wang F, Trentacost DJ, et al. Outcomes of cataract extraction with multifocal intraocular lens implantation: functional status and quality of life. Ophthalmology 1997; 104:589-99.

2 Post CT Jr. Comparison of depth of focus and low-contrast acuities for monofocal versus multifocal intraocular lens patients at 1 year. Ophthalmology 1992;99:1658-63.

3 Steinert RF, Post CT Jr, Brint SF, et al. A prospective, randomized, double-masked comparison of a zonal-progressive multifocal intraocular lens and a monofocal intraocular lens. Ophthalmology 1992;99:853-60.

4 Leyland M, Zinicola E. Multifocal versus monofocal intraocular lenses after cataract extraction (Cochrane review). J Am Coll Surg 2002;195:685.

5 Javitt J, Brauweiler HP, Jacobi KW, et al. Cataract extraction with multifocal intraocular lens implantation: clinical, functional, and quality-of-life outcomes. Multicenter clinical trial in Germany and Austria. J Cataract Refract Surg 2000;26: 1356-66.

6 Javitt JC, Steinert RF. Cataract extraction with multifocal intraocular lens implantation: a multinational clinical trial evaluating clinical, functional, and quality-of-life outcomes. Ophthalmology 2000;107:2040-8.

7 Desai $P$, Reidy A, Minassian DC, et al. Gains from cataract surgery: visual function and quality of life. Br J Ophthalmol 1996;80:868-73.

8 Orme ME, Paine AC, Teale CW, et al. Cost-effectiveness of the AMOArray multifocal intraocular lens in cataract surgery. J Refract Surg 2002; 18:162-8

9 Gold MR, Siegel JE, Russell LB, et al. Cost-effectiveness in health and medicine. New York, Oxford: Oxford University Press, 1996.
10 Drummond MF, O'Brien B, Stoddart GL, et al. Methods for the economic evaluation of health care programmes, 2nd ed. Oxford, New York, Toronto: Oxford University Press, 1997.

11 Nijkamp M. Determinants of patient satisfaction after cataract surgery. Maastricht: Unigraphic Maastricht, 2003.

12 The EuroQol Group. EuroQol-a new facility for the measurement of healthrelated quality of life. Health Policy 1990;16:199-208.

13 Dolan P. Modeling valuations for EuroQol health states. Med Care 1997;35:1095-108.

14 Torrance GW. Measurement of health state utilities for economic appraisal. $J$ Health Econ 1986;5:1-30.

15 Brown MM, Brown GC, Sharma S, et al. Utility values associated with blindness in an adult population. Br J Ophthalmol 2001;85:327-31.

16 Torrance GW. Social preferences for health states: an empirical evaluation of three measurement techniques. Socio-Econ Plan Sci 1976;10:129-36.

17 Torgerson DJ, Campbell MK. Economics notes: cost effectiveness calculations and sample size. BMJ 2000;321:697.

18 www.statistics.dnb.nl/index.html.

19 Azimi NA, Welch HG. The effectiveness of cost-effectiveness analysis in containing costs. J Gen Int Med 1998;13:664-9.

20 Friedberg M, Saffran B, Stinson TJ, et al. Evaluation of conflict of interest in economic analyses of new drugs used in oncology. JAMA 1999;282:1453-7.

21 Krimsky S. Conflict of interest and cost-effectiveness analysis. JAMA 1999:282:1474-5

22 Brown MM, Brown GC, Sharma S, et al. Quality of life with visual acuity loss from diabetic retinopathy and age-related macular degeneration. Arch Ophthalmol 2002;120:481-4.

23 Groot W. Adaptation and scale of reference bias in self-assessments of quality of life. J Health Econ 2000;19:403-20.

24 Adang EM, Engel GL, van Hooff JP, et al. Comparison before and after transplantation of pancreas-kidney and pancreas-kidney with loss of pancreas - a prospective controlled quality of life study. Transpl $1996: 62: 754-8$.

25 Postulart D, Adang EM. Response shift and adaptation in chronically ill patients. Med Decis Making 2000;20:186-93.

26 Donaldson C, Hundley V, Mclntosh E. Using economics alongside clinical trials: why we cannot choose the evaluation technique in advance. Health Econ 1996;5:267-9. 